
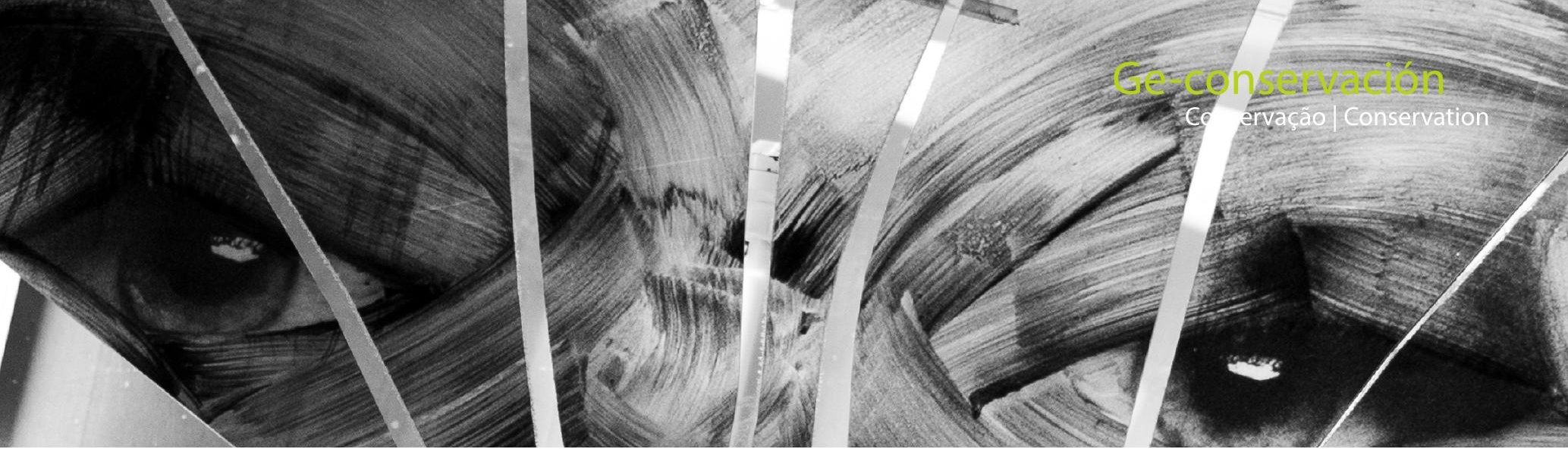

\title{
El espacio intermedio del arte urbano
}

\section{Elena García Gayo}

Resumen: El análisis de manifestaciones artísticas en el espacio público hace necesario ordenar el panorama. Se conocen con la etiqueta generalista de "graffiti" y"arte urbano" aunque estas dos fórmulas definen manifestaciones diferentes que solo tienen en común el espacio. Después de cincuenta años de existencia del graffiti (escribo mi nombre incansablemente) y algunos menos del arte urbano (interpreto y/o decoro el contexto), han sido asumidos por las instituciones y el mercado del arte, haciendo desaparecer las diferencias que los separaban, por más que en el ámbito académico estén ampliamente documentadas. Finalmente, el mercado del arte y la administración pública se han dado la mano apropiándose e intercambiando a voluntad ambas etiquetas "arte urbano" y "graffiti" que han resultado reapropiadas vaciando su contenido. Esto ha llevado a la creación de "museos de arte urbano", unos productos híbridos que pervierten tanto el primer concepto (museo) como el segundo (arte urbano). Para este estudio se propone un espacio imaginario común, el espacio intermedio, que ofrece la posibilidad de compartir propuestas artísticas. El único límite lo marca el uso de su particular terminología.

Palabras clave: street art, intermediate space, graffiti, urban art, muralism, creativity, conservation-restoration

\section{The Intermediate Space of Street Art}

Abstract: The analysis of artistic manifestations in public space makes it necessary to order the phenomena. They are known by the generalist label of "graffiti" and "urban art" although these two formulas define different manifestations that have only their location in common. Over the past fifty years, graffiti (I write my name tirelessly) and urban art (I interpret and/or decorate the environment) have been assimilated by cultural institutions and the art market, making the differences that separated them disappear, more so than in the academic fields in which they are widely documented. Finally, the art market and the public officials have agreed to appropriate and exchange at will the labels "urban art" and "graffiti" and by appropriating them, emptying them of meaningful content. This has led to the creation of urban art museums, hybrid products that pervert both the first concept (museum) and the second (urban art). For this study a common imaginary space is proposed, the intermediate space, which offers the possibility of sharing authentic artistic productions. The only limit is the necessary use of accurate and appropriate terminology.

Key words: street art intermediate space, graffiti, urban art, muralism, creativity, conservation-restoration

\section{Introducción}

Los diferentes usos artísticos del espacio público en el siglo XX han influido en la puesta en escena de lo que se conoce ahora como arte urbano [1] (Ulrich, 2015; Gayo, 2018a) y todos juntos establecen una herencia cultural de origen diverso, desde la que proviene de la crítica social de finales de los sesenta - el cuestionamiento competitivo y uso comercial del espacio público por algunos sectores del graffiti- hasta las fórmulas musealizadas más convencionales de exponer extramuros de los museos. En este punto de vista se significan dos tipos diferentes de intervenciones, las subvencionadas e institucionales, que son las que se reconocen como arte público y otras pequeñas y alternativas que toman el espacio de forma ilegal, que son las que se definen como graffiti y arte urbano. La fórmula legal subvencionada integra obras que sirven al fomento de intereses locales, casi siempre el turismo, y se articulan como exposiciones urbanas en pro del bien común y de la visibilidad institucional. En estas propuestas se intenta contar con artistas de reconocido prestigio que llegan a protagonizar la imagen de la propia iniciativa. En los casos mencionados, todos buscan la máxima visibilidad y llegar al mayor número 
de personas posible. Es innegable que en esta carrera ha ganado la batalla la fórmula ilegal, que finalmente ha conseguido filtrarse hasta llegar a las instituciones [figura1]

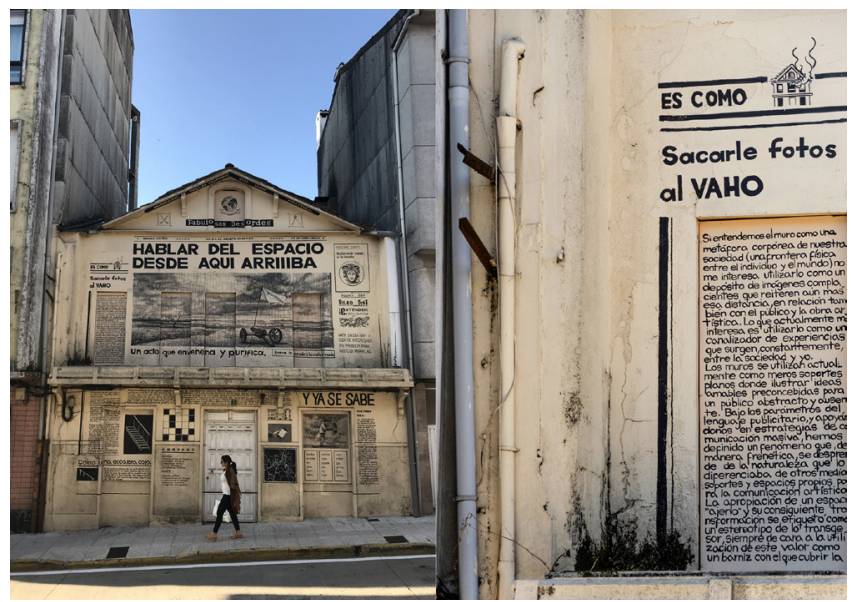

Figura 1.- Daniel Muñoz, alias San. Festival, Desordes Creativas. Ordes 2019. "JERGA", una pieza site specific que habla sobre las manifestaciones artísticas en el espacio público. "Hablar del espacio desde aquí arriba es como sacarle fotos al vaho, un acto que envenena y purifica: Entre lo crudo y lo calcinado..."

Aunque en este ascenso por capilaridad aún no hay lugar para la recompensa ni reconocimiento artístico, los artistas obtienen una gran repercusión posterior en el mercado del arte especializado y en galerías, es decir, aunque no llegan a ser admitidos en el ámbito público dedicado a preservar el patrimonio cultural, el mercado del arte se deja influir por esta esperanza. Sus obras no se disimulan en el espacio sino que alteran el propio contexto en el que se sitúan, del que se adueñan, y en el que se muestran como una piel vulnerable que recubre visualmente la arquitectura. La calidad efímera es una pantalla que evita el compromiso de conservación, que tantos quebraderos de cabeza da a las instituciones. Las obras que se generan no llegan a tener la consideración de obras de arte, pero consiguen ser el foco de atención mediática a través de la prensa. La ciudad es un campo de acción en el que los artistas experimentan muchas prácticas diferentes. Se puede decir que el arte de la calle se ha incorporado al arte público como una manifestación artística diferente que ha generado la necesidad de cubrir un espacio vital propio.

Por otra parte, el ámbito administrativo público también está cambiando y la muestra es el proyecto Percent for Art Program, que vio la luz en 1983 y sigue avanzando como un programa de arte público del Department of Cultural Affairs del Ayuntamiento de Nueva York, consigue desde la selección de obras y las temáticas elegidas, de máximo interés público, una relación de cercanía con los barrios donde se sitúan (ver artículo de Sergio Pardo López).

Parece que la variable de todos los proyectos artísticos urbanos es la manera de entender lo que significa trabajar en un entorno urbano, algo que resultó perfectamente descrito en la documentación generada para la exposición sobre arte y espacio público del Centro Atlántico de Arte Contemporáneo de Las Palmas de Gran Canaria, en la que Ramón Parramón (2009) describe como imprescindible la necesidad de establecer unos mecanismos de negociación y de mediación donde el trabajo artístico y la relación con el lugar y el espacio social puedan encontrarse y extraer elementos de interés, basados en una relación recíproca. También identifica el resultado obtenido con un servicio público, dónde hay un beneficio colectivo generado por el intercambio de conocimientos. Reconoce la actividad artística como un campo de batalla en el que, finaliza, "los nuevos centros de producción de arte no pueden eludir su participación" (Parramón 2009). No podría ser una descripción más acertada del espacio intermedio en el que desarrollar la actividad artística urbana.

En este texto, a continuación, se compararán varias iniciativas con la intención de extraer unas directrices que ayuden a definir fórmulas de exposición que fluyan de su propia esencia. Como novedad, en este nuevo rango artístico urbano, se observa que se acude a los artistas, fundamentalmente, porque son reconocidos y valorados por los mass media, que no es sinónimo de valor artístico.

No se entrará a definir ni analizar lo que es un museo ya que está desarrollado en varios artículos de este mismo monográfico y resultaría reiterativo (ver artículo de Diego Ortega y Juan Jesús Padilla). Sólo mencionar que la dificultad para actualizar la definición de museo por parte el ICOM [2] aparece, de cara a la opinión pública, como una necesidad de anclar las instituciones al pasado sin permitir su avance, algo que tampoco facilitaría la apertura y crítica hacia esta institución desde los planteamientos de las tendencias artísticas urbanas actuales, algo que establecería una interesante relación.

\section{Metodología}

El presente trabajo se basa en más de setenta entrevistas a artistas con actividad en el espacio público, gestores de grandes eventos y personas involucradas en el estudio y difusión de la expresión artística en entorno urbano [3] (Capel, 1975:265-301), además de en la consulta de bibliografía especializada en cada una de las materias involucradas. Se identificarán nexos de unión entre diferentes manifestaciones artísticas desarrolladas en el espacio público, fundamentalmente las que han usurpado la etiqueta "arte urbano" cuando su denominación pública no está sujeta a las mismas reglas y forma parte del muralismo contemporáneo o a intervenciones artísticas actuales. Se parte de un planteamiento transversal, que busca planificar la mejor manera de exponer arte en el espacio público y que tiene que ver con las buenas prácticas en Conservación- 
Restauración, en las que se considera fundamental tener en cuenta la opinión y percepción del artista [4]. El hilo conductor del análisis se inscribe en un espacio intermedio imaginario que permite una relación sin fricciones y desde el cual se pueden analizar las diferentes influencias sobre las obras de arte desarrolladas en la calle teniendo en cuenta la motivación -que define su razón de ser-, el proceso creativo - que se sitúa entre la idea y la motivación de cada obra de arte urbano-, y por último, sus posibilidades de permanencia.

Se definirán los espacios intermedios como:

1. Espacio intermedio para la creatividad,

2. para la comunicación,

3. público y privado, regulados,

4. colaborativo,

5. entre lo efímero y lo perdurable.

\section{Espacio intermedio para la creatividad}

Es un espacio tan material como temporal, que tiene que ver con el instante de creación de una obra y que se presta a muchas combinaciones, tal y como se verá a lo largo de esta exposición. En el caso del graffiti y el arte urbano, su soporte es de una variedad infinita, aunque la máxima visibilidad es de las medianeras de edificios. El espacio público conquistado por el graffiti es el que más encajaría en esta definición, porque, como afirmaba Juan Antonio Ramírez (1992:197-207) "¿no será el arte verdadero una cosa clandestina? Los graffiti neoyorkinos desde luego si lo son". Y siendo simples capas de pintura, ¿por qué resultan siempre tan perseguidos? [figura 2]

El graffiti actual, heredero del de los setenta, viene también del mundo adolescente, dónde hay una necesidad de reafirmación personal y única del ego. Representa a una voz exenta de ideología política. Con el tiempo, los propios writers han revolucionado la expresión artística urbana y

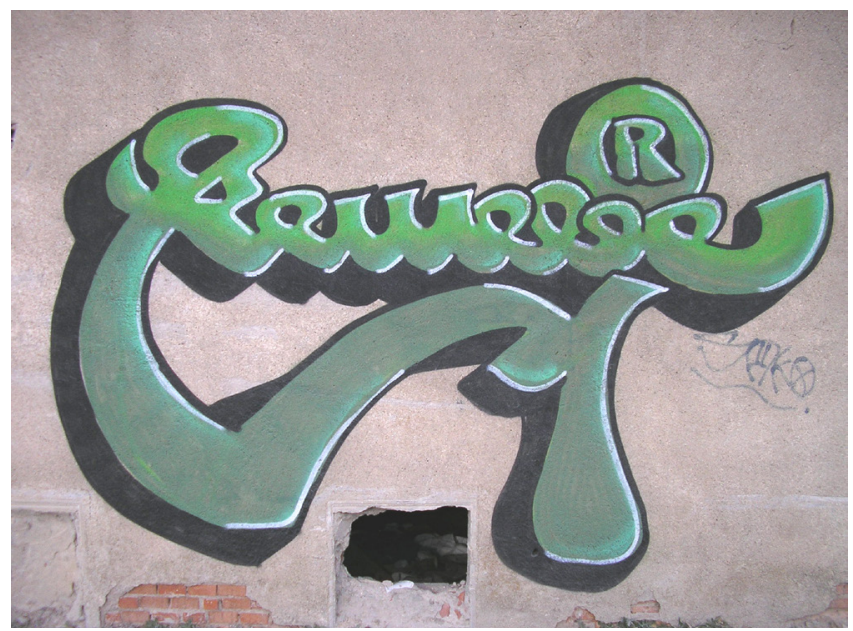

Figura 2.- Pieza en grosor de estilo flechero. Autóctono madrileño. Remebe. Loeches. Madrid. 2005. han conseguido contagiar a más artistas con su forma de transitar el mundo. Es una necesidad de expresión innata en el ser humano, que se realiza sin esperar nada a cambio y con la única ambición de dejarse ver y abrirse al mundo (Craig Castleman, entrevista anexo). Los Hall of Fame, espacios de máxima afluencia de escritores en cada ciudad, son el centro de reunión de cada círculo social del graffiti y constituyen unos espacios expositivos imprevistos. En ese viaje personal de conquista por la ciudad se descubren de forma intuitiva los espacios de mayor visibilidad y sorpresa. Esta particularidad resultará aumentada por el espíritu crítico de las obras y los planteamientos de los artistas activistas.

Por su parte, el arte urbano utiliza el espacio público como espacio de creación, exposición y difusión al mismo tiempo, es decir, las obras site specific se crean en un espacio y lugar concretos. Son obras en contexto y realizadas para la sorpresa. Sirva como ejemplo la acera tallada del escultor Ken Hiratsuka que empieza sus "fósiles del momento" en 1983, año en el que talla la primera línea interminable en la esquina de Prince con Broadway, en Nueva York. Aquellas primeras obras continúan hoy en la calle. Han sido erosionadas por el paso del tiempo y el roce de millones de pisadas, sus improntas estarán unidas para siempre a la historia material de un pavimento que sin esta obra no tendría un significado sentimental tan especial. [figura 3].

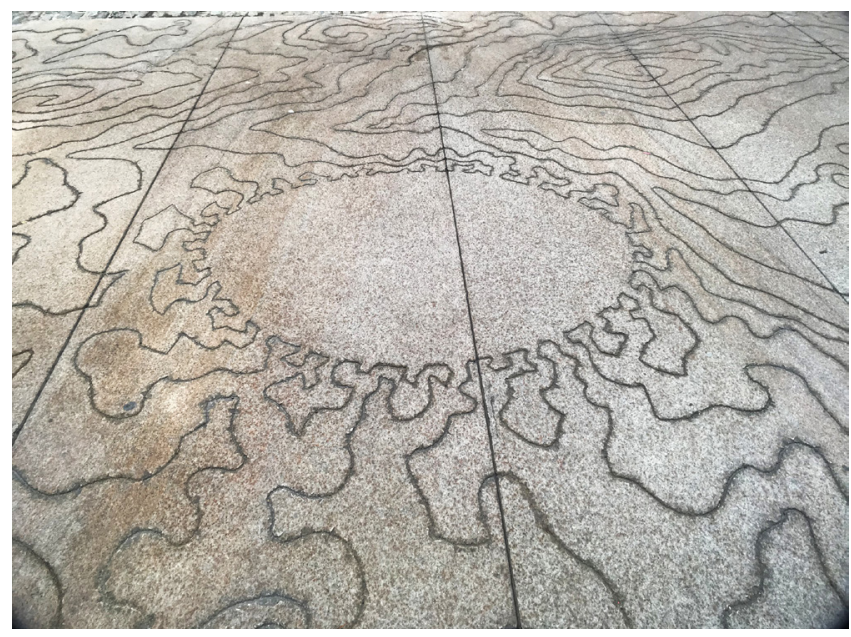

Figura 3.- Obra de Ken Hiratsuka en Nueva York. Foto de Jaime Rojo. Brooklyn Street Art

En este caso, el espacio urbano es también un espacio intermedio de vital importancia, porque para un artista la calle da sentido y vida a su producción. Al llegar a la galería las obras expuestas son el resultado de esa experiencia (Nuria Mora, entrevista anexo). Las obras que se exponen en los llamados "museos de arte urbano" - a las que sería más apropiado llamar arte actual- son la consecuencia de la experiencia de trabajar en la calle con el contexto, que consigue transformar y formar a la persona como artista. Como resultado, las obras de galería 
son la conclusión de un trabajo intelectual que finaliza en una obra "enmarcada". Esto sucede con todas las obras artísticas, tengan la forma que tengan, pero el interés del arte en el espacio público es que, aunque se intervenga en la calle, no es trasladable, puesto que lo que viaja a la galería es la experiencia transformada del artista. Es la esencia y conclusiones del artista, las que se enmarcan dentro de los espacios expositivos. En esta práctica, según San (entrevista en anexo) están "todos los elementos que se conjugan en una pieza" y hablan del propio proceso. Aluden a lo que interviene en la mirada, de la historia, de la construcción, del lenguaje. "El proceso, que serían las pautas a seguir: el orden que intentas controlar en el pensamiento, el ciclo que sigue una idea; todos esos conductos por los que transito mentalmente, intento provocarlos y que la gente pase por lo mismo que he pasado yo".

Dentro del proceso creativo puede haber tantas conclusiones y recursos como sea posible imaginar. Las obras así ejecutadas —entre la calle y la galería- pueden verse alteradas o no. En el caso de la obra de Vermibus, eminentemente activista y urbano, no podría existir la segunda parte sin la primera, aunque, en este caso concreto, las obras no cambian en el traslado pero no se entenderán sin conocer el contexto original del que emergen (Gayo, 2018b).

El resultado final es una interpretación del funcionamiento imperfecto del sistema. No puede afirmarse que la parte que se expone sea arte urbano, porque no lo es, aunque es evidente que todos los pasos del proceso creativo que lo han provocado sí lo son. Esto quedó muy bien expresado con la obra de SUSO33 I-legal, de 2013, en la cual su famosa plasta estaba pintada sobre un panel y apoyada en un muro de la calle, debajo escribió "Ilegal". Al separar el panel quedaba fuera la "i" y dentro del panel se leía "legal" y fue esta parte recortada la que se expuso de una forma coherente en una sala de exposiciones. De esto se deduce que el arte urbano no podrá ser nunca expuesto en un museo sin resultar alterado, aunque puede llegar a ofrecer una visión diferente e interesante relacionada con los elementos que lo rodean. Las obras de la calle que se exponen en museos y galerías tendrán que ser siempre consideradas como arte urbano sustraído, trasladado o apropiado, si esa posibilidad no ha sido prevista y justificada intelectualmente por el artista.

\section{Espacio intermedio para la comunicación entre el artista y el espectador}

El espacio urbano para la comunicación se definiría como aquel en el que se desarrollan los procesos y se construyen tipologías artísticas diferentes (pintura, escultura, mural, instalaciones...). El espacio entre la obra y el espectador es aquel que tiene en cuenta este diálogo a través de las obras. Su interacción puede definir el tipo de espectador, clasificándolo, por ejemplo, en testigo, invitado, enemigo, protagonista o coproductor (Matewecki, 2014).
Hay que resaltar que la clasificación del espectador elegida no es gratuita, sino que ayudará a detectar aspectos importantes que definirán cómo es la relación entre éste, la obra y el contexto; algo que en el arte urbano y el graffiti es importante. El espectador del graffiti es el espectadorenemigo, si no es bien recibido, ya que va dirigido preferentemente a sus iguales y sólo es entendido por ellos. En el arte urbano, por el contrario, se comunica con el entorno y en sus obras hay implícita una relación con los vecinos, el barrio o la ciudad que se podría llegar a medir y valorar. Si los elementos que se conjugan en las piezas están hablando de lo que interviene en la mirada, lo que procede de la historia, de la construcción o del lenguaje, será el proceso lo que marcará las pautas a seguir en el viaje inverso del espectador para descifrar la obra y lo que le convertirá en espectador protagonista, si fuera el caso.

Se tendría que definir también cúal es el papel de los artistas, que tampoco se libran de clasificaciones. Suzanne Lazy (1995) los clasifica en experimentados, informados, analistas y activistas; y estos últimos también pueden ser los herederos de las inquietudes políticas generadas a finales de los años sesenta y principios de los setenta (Aznar, Iñigo, 2007). Estas definiciones no deben tomarse como compartimentos estancos, ya que cuando se habla de arte y de expresión en medio urbano los límites se pueden difuminar. Por ejemplo, desde el punto de vista de Vermibus, "la obra es principalmente una comunicación unilateral, por lo que no considero que la obra en sí misma sea una conversación con el público, sino más bien con la industria. Mi obra es una respuesta a su mensaje" (ver entrevista Vermibus en anexo).

\section{Espacio intermedio musealizado}

Desde las instituciones lo que se promueve es la presentación pública de espacios para la promoción local cuyo ejemplo son los murales de los ochenta, muchos de ellos mediante financiación del Fondo Europeo de Desarrollo Regional (FEDER) y cuyo objetivo era embellecer las ciudades. En este caso, el espectador es un invitado y a la vez un observador, y los espacios se ceden con espíritu de ser obras de arte listas para observarse a distancia, con esa distancia que marca la línea museal de "no pasar", "no tocar". De ahí viene la tradición más cercana en el tiempo de los museos al aire libre, porque son los museos los que salen a la calle a mostrar sus obras. Estos espacios cedidos al arte por los ayuntamientos acusan en su iniciativa un cierto fracaso de las instituciones, ya que se identifica la necesidad de salir al exterior con una solución para solventar la insuficiencia de público en el interior y un deseo de atraer visitantes de un nivel cultural medio. Porque el rigor científico y la didáctica de las colecciones expuestas no son suficientemente eficaces para llenar los pequeños museos locales que se dedican a preservar colecciones de todo tipo. Un ejemplo fallido es el caso del Museo de Escultura al Aire Libre del Paseo de la Castellana de Madrid, poco conocido y visitado. Ahora, el arte debe ser 


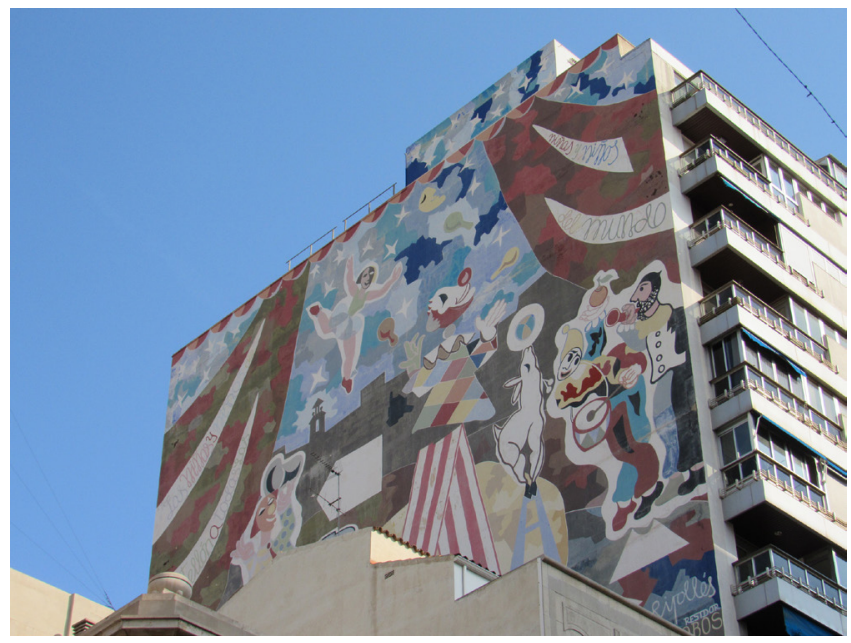

Figura 4.- Mural de Ripollés en Castellón. Foto de Mayte Pastor Vals

espectáculo y es eso lo que se quiere ofrecer a los visitantes. El arte en la calle se ofreció en el pasado como reclamo turístico dentro de iniciativas como el Museo al Aire Libre de Castellón, en el que la buena calidad de los materiales utilizados en los años ochenta permitió a las obras llegar a nuestros días en buenas condiciones [figura 4].

Calvo Serraller (1983) describe el Museo Abierto de Fuengirola como "Arte Urbano" en un artículo en el que enumera las características que debe tener un museo al aire libre. En su descripción la principal es el criterio de rigurosa selección de los bocetos y, por tanto, de los artistas, cuyas obras murales se ejecutan por pintores profesionales supervisados por los artistas. En segundo lugar, la versatilidad de los soportes que, en principio, parecían facilitar el traslado de las obras, pero con el tiempo ha sido algo imposible de realizar, ya que se utilizaron planchas de fibrocemento, polvo de amianto, de elevada y reconocida toxicidad. Y la tercera de las cualidades enumerada como importante, es la participación del pueblo de Fuengirola en un rol que se podría describir como de espectador-testigo, ya que su colaboración se queda en la financiación de los proyectos a través del ayuntamiento.

En 1994 y según el artículo de Paz Bernal (1994) de la mano de los artistas José Antonio García Álvarez, Fernando Álamo y Manuel Padorno se interviene en las medianeras del paseo de las Canteras de Las Palmas de Gran Canaria para celebrar el fin de las obras de acondicionamiento y modernización de las instalaciones de esa primera línea de playa. El hilo conductor es un poema de Tomás Morales que se planteó como un juego de color. Un usuario imaginario vería al ir a la playa las medianeras ejecutadas con colores fríos y a la vuelta las de colores cálidos. Eran conscientes de que se trataba de pintura efímera, de la que solo queda una medianera de Manuel Padorno y muy repintada a lo largo del tiempo, aunque se han respetado las líneas originales. Los artistas hablaban de salir a la calle para darse a conocer a un público más amplio y no quedarse en el círculo de los que podían conocerlos en las galerías. La ejecución, igual que en Fuengirola, la llevaban a cabo pintores de fachadas, usando las plantillas que se les facilitaba y bajo supervisión de los artistas.

El Museo de Pintura al Aire Libre de Candás, en Asturias (Vaquero, 1980), es diferente a los anteriores ejemplos, porque está profundamente vinculado al espacio y a su población. Comprometidos desde los inicios con la memoria histórica de la localidad, desde 1979, van adaptando la expresión artística local al paso de los años bajo la mirada de los artistas invitados. Señalar que en sus inicios fue una iniciativa privada que, tras varias etapas y desapariciones, se retomó asumida por el ayuntamiento.

\section{Espacio intermedio virtual}

Este espacio es el que da visibilidad a todo un colectivo de artistas que ha nacido con Internet y cuya formación está ligada a las nuevas tecnologías. A diferencia de los planteamientos institucionales, el aspecto en el que el arte en el espacio público es más libre es en el que se comparte sin esperar la presencia de un observador especializado. La sorpresa se valora como un descubrimiento íntimo y una experiencia personal única. A este instante le sigue el análisis de lo representado y la posibilidad de descubrir más datos sobre la obra y su autor, con la experiencia vivida del contexto, que es un añadido. Es lo más parecido a entrar materialmente en una obra. En la era tecnológica los espectadores-colaboradores se convierten también en intérpretes de lo que ven y participan de su difusión. Martha Cooper se pregunta "ise podría imaginar qué pasaría con el llamado arte urbano si Facebook o Instagram desaparecieran?". Y ella misma se contesta "todo desaparecería" (ver entrevista en anexo). En este entorno la experiencia sólo la vive una persona, pero es a la vez compartida por muchas.

Por otra parte, el graffiti y el arte urbano se han abierto al uso de soportes virtuales donde resultan manipulados y reutilizados, su calidad efímera es nula, porque en la red se convierten en obras inmortales. Las reglas las marca la demanda de internautas y la voluntad del artista desaparece en una apropiación, aparentemente, sin reglas. Todo en favor de una visibilidad artística sin límites. El espacio tecnológico, la tecnosfera, es un nuevo soporte del que ya no se podrán desligar pero, como comenta Sixe Paredes (entrevista en nexo) "aunque desaparezca la materia original, la imagen de tu obra en Internet existe y te pertenece". Spok va más allá, menciona Internet como el soporte real del arte urbano (entrevista en anexo).

\section{Espacio público y privado regulados}

El espacio intermedio regulado es el que se sitúa en el límite entre lo público y lo privado, donde está la fina capa de enlucido de las medianeras. Se podría definir como la parte visible de un espacio privado. Una capa que es susceptible 
de tener una utilidad social gracias a su visibilidad pública, aunque no está exenta de convenciones. Querer agradar, ser complaciente, se refleja en los temas elegidos de muchos murales que llegan a ser descritos como enlucidos meramente decorativos, que no tienen nada que ver con el contexto en el que se sitúan y no llegan a crear ningún vínculo afectivo con su entorno. Aquí se mencionan fundamentalmente obras murales, por cantidad, pero existe una gran variedad de soportes callejeros como OPIS, MUPIS, marquesinas y vallas, entre otros, que sirven como soportes artísticos y que forman parte de ese espacio intermedio entre lo público y privado.

Tal y como sucede con las obras colgadas en una sala de un museo, todas y cada una de ellas, están esperando a ser descubiertas y que alguna mirada se deposite conscientemente a desgranar su contenido. En ese punto, la mirada muta en deseo y posesión de la idea, con la cual, las obras adquieren un nuevo significado. No se puede dejar de lado la asociación mental del arte en el espacio público con el coleccionismo, que siempre va unido al poder político, el mercado, la cultura y la dominación, a fin de cuentas (Yvars, 2005:314). El coleccionista de arte urbano puede ser también objeto de clasificación, desde sociológica y económica a psicoanalítica, lo que puede ser buen material de estudio.

\section{Espacios controlados}

La administración no promueve espacios para la libre expresión. Es decir, espacios que resulten alternativos a las salas de exposiciones y que estén situados en el espacio público, en los que pueda haber una expresión artística realmente independiente y no fiscalizada. El muro "Por la Paz" (1982) promovido por el alcalde Enrique Tierno Galván, en la plaza del Carmen de Madrid, quiso serlo, pero nunca lo consiguió. Su parte baja, se anunciaba como un espacio para la libre expresión de ideas de los madrileños, aunque su diseño resulta pobre y es casi más valioso como documento histórico. "Un espacio para decir lo que uno piensa, con la coherencia de lo permitido" decía la nota de prensa de su presentación [5].

\section{Espacio intermedio para un graffiti y arte urbano "utópicos"}

La convergencia de los destinos del graffiti y arte urbano son evidentes en un tiempo de publicidad salvaje. Las modas calan en la sociedad adueñándose de símbolos generacionales y las marcas de ropa lo compran todo. "La notoriedad frente a una comunidad y también la búsqueda de un sentimiento de podery un respeto social descansan ahora en la exposición a través de los medios y en la participación en la industria-mercado" (Fernando Figueroa, entrevista en anexo)

Dondi (1961-1998) artista y escritor de graffiti, fue uno de esos ejemplos, que experimentó el cambio. De pionero del graffiti del metro de Nueva York a exponer en los Países Bajos y Alemania, con obras en varios museos europeos. Una de sus piezas ha sido finalmente subastada en Artnet, en 2017 y adjudicada por 240.000 USD. Esto es algo que siempre se había intentado desde las galerías como lo demuestra la experiencia de Lee Quiñones (Puerto Rico 1960) de los Fab5 con su salto al mercado del arte internacional. A Lee se le atribuye uno de los primeros trenes enteros pintados, en el Nueva York de los años 70 - aunque fueran realmente CAINE, MAD 103 y FLAME ONE los primeros (Castleman 1982:36-40) - y pasó, igual que Dondi, a pintar en la galería Medusa de Roma en 1979. "Si algo ha cambiado en el grafiti es la aparición del mercado del arte" (Martha Cooper entrevista anexo).

Diez años después, en España, Juan Carlos Argüello Garzo, Muelle, (Madrid 1965-1995), era el reclamo de la modernidad en ARCO 89, en la galería Estiarte. Otro de los principales representantes españoles de esta corriente multidisciplinar que va de la calle a la galería es SUSO33, que se inicia en el graffiti y reúne en su trayectoria toda una experiencia de tránsito de la calle a la galería a través de la experimentación en multitud de medios (entrevista en anexo).

Esa penetración en el sistema del arte marcará definitivamente a las nuevas generaciones, hasta tal punto de que "el mercado, unido a los certámenes institucionales, conseguirán finalmente dividir el grafiti en dos: uno legal, domesticado, y otro ilegal" (Fernando Figueroa, entrevista en anexo). Al mismo tiempo y como respuesta se prevé una intensificación dentro del graffiti, al que vuelven muchos de los artistas como una manera de recuperar su identidad y para mantener su vigencia dentro del propio colectivo. En este punto de inflexión, quizá, se pueda empezar a relacionar estas dos manifestaciones artísticas autogestionadas como graffiti y arte urbano "utópicos" para diferenciarlas del graffiti y el arte urbano institucionalizado, ya que en esta definición idealista nunca podrán llegar ser reconocidos sus valores sin que exista un riesgo de perder su razón de ser.

\section{Espacio intermedio para un nuevo arte público}

Sin querer entrar en mayores descripciones que se escaparían del objetivo del presente artículo por la amplitud del espacio necesario, el término arte público está en proceso de modernización y de permanente actualidad por el debate político que suscita. El arte en el espacio público viene de finales del siglo diecinueve, cuando se convocó el primer congreso (Abreu, 2010:17-29) [6] en el que sus objetos artísticos eran mayoritariamente monumentos institucionales. Lo cierto es que el arte público de finales del siglo veinte en España se nutrió con el 1\% cultural, obligado por la ley de Patrimonio Histórico, dedicado a obras públicas y que sembró el paisaje nacional de esculturas que muchas veces eran ejecutadas por los ingenieros y arquitectos que intervenían en los proyectos.

Las instituciones entienden la manifestación artística en el espacio público como actos festivos y conmemorativos de 
acercamiento intergeneracional y la marca "arte urbano" consigue fácilmente la visibilidad mediática perseguida, aunque una institución sólo pueda llevar a cabo arte público porque se rige por las siguientes premisas:

a) Su instalación en el espacio urbano debe autorizarse. b) Las obras deben registrarse, aunque sean efímeras, porque se subvencionan con dinero público. c) Sus autores deben gozar de reconocimiento, puesto que deben cobrar un servicio. d) Las obras son, la mayoría, de lectura fácil, o muestran varios niveles de expresión, porque el público es muy variado. e) Están respaldadas por la utilidad pública de su entorno o por asociaciones locales que pueden hacer uso de esas instalaciones mejoradas.

Conforme a esa voluntad de promoción artística y cultural, es evidente que los artistas, conocidos como "artistas urbanos", en estos casos, ejecutan obras de carácter público, aunque la administración ceda sus competencias a entidades privadas para llevar a cabo murales monumentales. La etiqueta es más publicitaria que real. Algunas instituciones ceden también sus funciones de comisariado a galerías, asociaciones y empresas privadas a las que subvencionan. En estos casos se invierte el sentido de lo público convirtiendo el territorio en un espacio privado para unos fines de promoción indefinida. Se evita, así, cualquier tipo de responsabilidad posterior y no existe la necesidad de registro, tutela ni reconocimiento de los artistas que han generado unas obras efímeras de disfrute público. Las obras se ejecutan con materiales que van a sobrevivir una media de siete a diez años, en el mejor de los casos, y no se crea ninguna vinculación institucional con ellos. Por otra parte, las instituciones siempre van a resultar beneficiadas por el interés mediático que despiertan estos artistas en otros países.

Tal y como se puede ver en muchas de las entrevistas del anexo, los artistas se plantean estas intervenciones subvencionadas de forma diferente a como las abordarían de una forma independiente o para una galería. Los espacios que se ofrecen van siempre más allá de cualquier expectativa, porque son espacios públicos a los que no tendrían acceso de otra manera sin asumir una importante multa y la ventaja que supone contar con todos los medios necesarios.

Existe, pues, un doble rasero para considerar el acceso a algunos muros, ya que la mayoría de ellos se liberan para ser pintados por un objetivo de visibilidad y con un proyecto justificado y aprobado por la institución que los promueve. Según el criterio de San (entrevista en anexo) "Uno de los pilares más importantes de mis obras es sobre la regularización de mi trabajo. Del arte público y de cómo se pueden mantener unos patrones para que esa insolencia, rebeldía, un poco adolescente, y su espontaneidad, representada en algunas de mis obras, no se pierda. De cómo una de esas obras insolentes puede llegar a ser inaugurada por el presidente de una comunidad autónoma. Incluir toda esa fricción, ese conflicto que genera, forma parte de mi trabajo". [figuras 5 y 6 ]
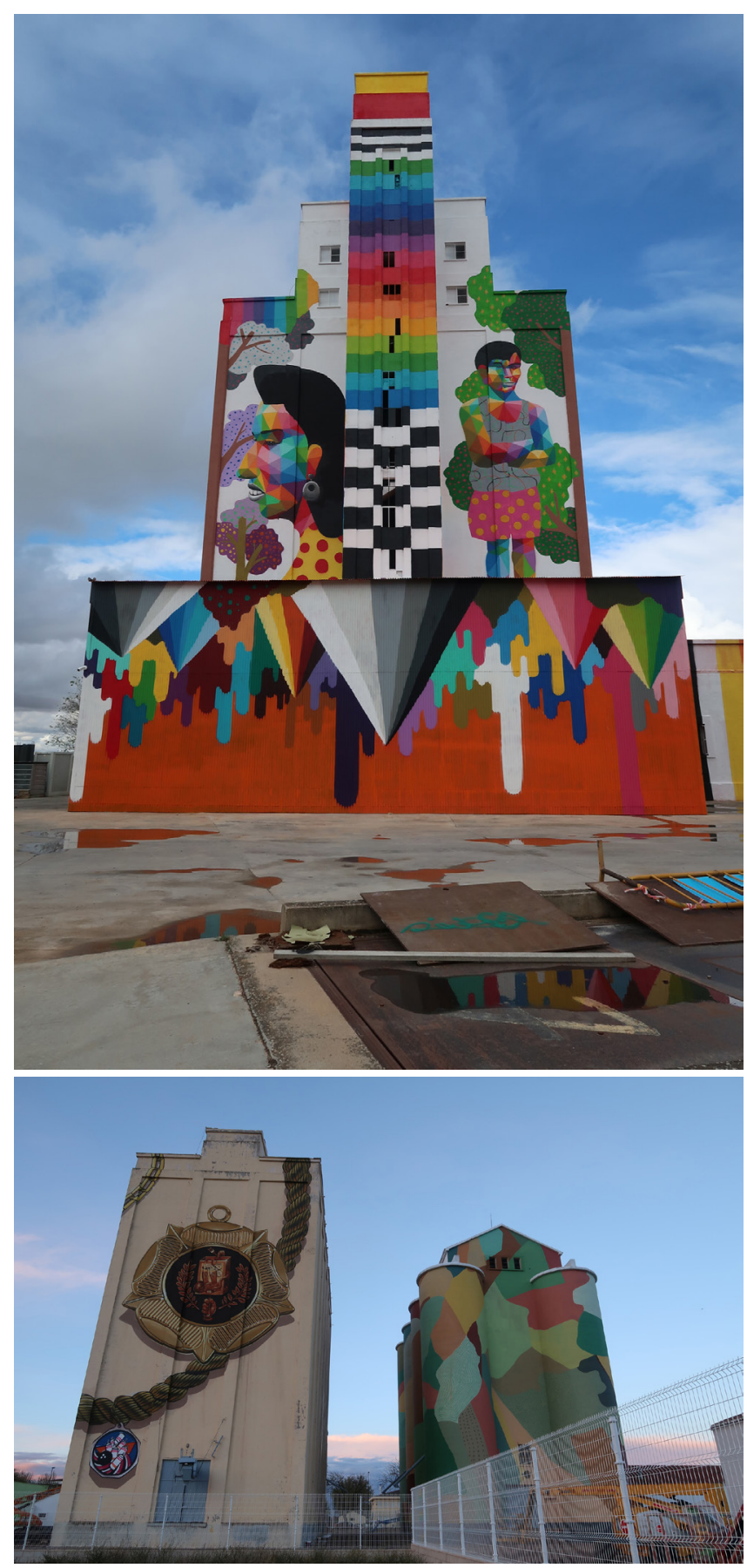

Figura 5 y 6.- Izquierda: Proyecto Titanes. Silo de Calzada de Calatrava. Okuda. Ink and Movement. Derecha: silos de Manzanares durante el proceso: San y Spok y Equipo plástico: Nuria Mora, ElTono, Sixe. Nano 4814

La "España vacíada" ha dejado un buen número de iniciativas que se pueden referenciar con la seguridad de que hay muchas más, alguna de ellas ha sido analizada en artículos de este mismo monográfico. Sólo mencionar las que han podido tener una mayor repercusión mediática: Fanzara, Cambre, Carballo, Ordes, El Provencio, Campo de Criptana, Castrogonzalo, Penelles, Romangordo, Fresnedilla de la Oliva, Tubilla del Lago, La Bañeza, Tudela, Villangómez y una de las últimas, las famosas intervenciones en los silos de la provincia de Ciudad Real localizados en Calzada de Calatrava, Corral de Calatrava, La Solana, Herencia, 
Malagón, Manzanares y Porzuna. Este es un mínimo listado de pequeños municipios y aldeas cuyos muros han sido utilizados como soportes artísticos, algunos de ellos con la esperanza de recuperar su visibilidad y no desaparecer. Al mismo tiempo, se deja notar la penetración en temas artísticos urbanos por parte de las políticas institucionales en las que se sitúa el foco en pequeños municipios, aunque no existan proyectos estables que perfilen la posibilidad de promoción e investigación con los que apoyar a los artistas.

La diferencia en algunos de estos casos es también evidente cuando los vecinos, a través de asociaciones locales, se convierten en espectadores-colaboradores con proyectos de desarrollo local, como es el caso de Fanzara, ya que esto garantiza el éxito de la iniciativa. Se facilitan encuentros en pequeñas localidades que de otra manera serían imposibles. Se mezclan talleres con espectáculos musicales que cambian la visión del mundo de muchas personas que nunca han salido de los límites de sus municipios. En estas iniciativas tan enriquecedoras como ilusionantes se da alojamiento a los artistas y algunas veces las familias mantienen unos lazos de continuidad con ellos.

Todas las propuestas son válidas, siempre que no se denominen arte urbano y se empiecen a utilizar etiquetas propias como ha sido el caso de Parees Fest de Oviedo, Asalto de Zaragoza (entrevistas en anexo) y Murales Conciencia de Bailén (con artículo en este monográfico) son buenos ejemplos de esta corrección en la terminología y una pequeña muestra de las posibilidades.

\section{Espacio intermedio colaborativo: festivales y gestión cultural. El camino de lo institucional a lo procomún}

Es el espacio que se mueve entre lo institucional y lo asociativo haciendo visibles a sus promotores. Espacios de colaboración que se dan normalmente fuera de las instituciones y muy pocas veces dentro de ellas, aunque son propuestas subvencionadas que incluyen al espectador y que bajo esa clasificación mencionada al principio resulta ser el coproductor de las iniciativas. La imposibilidad de realizar estas propuestas íntegramente desde la administración está marcada por el ritmo necesario para realizar los ajustes que van surgiendo dentro de la propia dinámica de las propuestas (Sánchez, 2003).

Ese camino iniciado por el arte en espacios públicos en el siglo XXI tiene su inspiración en el movimiento digital open source, basado en la idea de compartir el conocimiento de forma abierta para conseguir un método colaborativo y empoderamiento social. En 2009, con el premio nobel de economía a Elinor Ostrom y la demostración de la posibilidad de desarrollo a partir de recursos compartidos y el fomento de bienes comunes, se empieza también a entender el espacio público de otra manera.

Algunas experiencias pasadas de museo en la calle —aún en la memoria-, son las que han hecho más fácil la aceptación de un buen número de artistas para recuperar esa actividad. Procedían de una situación de subsistencia — basada en la gratuidad de sus producciones-creada por la crisis económica, que resultó agudizada en el ámbito cultural y dejó a muchos artistas sin salidas profesionales porque el sistema no era capaz de asumirlos. Las exigencias de las galerías y ferias de arte siempre han sido un filtro que no todos han estado dispuestos a pasar para ganarse la vida, aunque siempre se termine aceptando, tal y como reconoce Okuda (entrevista en anexo).

Por otra parte, la sociedad necesita recomponerse y recuperar la protección cultural perdida en los años de profunda crisis económica y beneficios sociales, desde 2007 2008, en los que se llegó a hablar del "arte boicot", desde el que se declinarían invitaciones a no participar en muestras "por amor al arte" y sin medios. La alternativa estaba en la calle, representada por una legión de artistas que de forma autodidacta salían a conquistar lo que se les negaba, un espacio vital, y se formaron en la ejecución de obras en formatos murales monumentales. Artistas con el respaldo de ser en un elevado porcentaje titulados superiores, los más numerosos en Bellas Artes, Diseño y Arquitectura (Gayo, 2011). Esto ha unido a dos sectores necesitados, uno de un medio de vida y otro de visibilidad; con esta alianza se ha dado luz a diferentes proyectos que se han abordado desde muchos puntos de vista dando lugar a festivales, concursos, "museos", proyectos artísticos que se desarrollan a través de residencias, culturales, asociativos y un largo etcétera. Alguno de ellos representado en entrevista en el anexo de este monográfico por sus gestores y comisarios.

Los artistas tampoco son todos iguales y sus propuestas van desde las meramente decorativas a las activistas y solo algunas se consideran obras con interés artístico. En ese universo urbano, la falta de jerarquías y de críticos profesionales formados y especializados-dispuestos a crear opinión, que ayude a ordenar la escena, hace que aumente la confusión a la hora de valorar las obras que se encargan. "Los gestores culturales actúan como comisarios y son parciales", suplen lo que debería ser un criterio objetivo de coleccion pública, situación que lejos de aclarar el panorama artístico actual, lo ensombrece (Nuria Mora, entrevista en anexo).

Como se ha apuntado, en las intervenciones de este espacio intermedio, en el que hay asociado un proyecto local y también hay obras de un elevado nivel artístico que, si no llegan a identificarse con el territorio, quedarán en el olvido y se convertirán en invisibles. Su degradación será bien recibida y los muros acabarán repintados. No quedará nada más que el agradecimiento de su calidad efímera.

\section{Espacios entre lo efímero y lo perdurable}

El espacio intermedio desde la conservación, un espacio temporal entre lo efímero y lo perdurable, es necesariamente interdisciplinar. Se podría definir como el punto máximo de deterioro que el artista está dispuesto a aceptar en su obra 
antes de que desaparezca. Dejarlas envejecer hasta ese punto - los materiales usados en expresiones artísticas callejeras son muy degradables y su conservación no se puede garantizar - y alargarles un poco más la vida. A muchos artistas les gusta ver la degradación de sus obras porque aprecian un cierto romanticismo en este deterioro, aunque hay un punto en el que dejan de entenderse y ese es el que hay que evitar si se quiere frenar su envejecimiento. Se puede conseguir que una obra se degrade lo más lentamente posible hasta que ya no exista la generación que la creó o cuando deje de estar en el punto de mira de su entorno y caiga en el olvido. Veremos algunos ejemplos, en cuanto a la posibilidad de seguimiento.

Si se decide desde el proceso creativo que las obras tienen que ser perdurables en el tiempo, esto requieren materiales y técnicas concretas con las que deben contar los artista en la ejecución. Estas propuestas tienen un espacio de intercambio que puede ir desde el juego intelectual al material, ya que se decide la paulatina degradación de los materiales con una doble simbología y la posibilidad de crear varios registros en una misma representación, tal y como lo ha contemplado Gonzalo Borondo en VitoriaGasteiz. Las dos intervenciones diferentes, superpuestas, en el mural "Lore Beltza" llevado a cabo en el marco del VI Congreso del GE-IIC en 2018, hablan sobre esto. La obra perdurable fue ejecutada con una preparación previa y silicatos, sobre la que se realizó una segunda intervención, final, experimental, en la que se aplicó una capa final efímera. Esto permite que el artista tenga dos registros diferentes de una misma obra. La capa efímera se irá perdiendo con el tiempo y dejará a la vista la capa original al silicato (Gayo, 2019) [figuras 7 y 8]

Las intervenciones de restauración dirigidas a alargar la vida de las obras, ya sean meramente preventivas o más intervencionistas, juegan un papel importante porque actúan como marcador de su reconocimiento por la sociedad. Este reconocimiento llega a formar parte de ellas y puede alterar su percepción futura si hay una tutela del estado que antes no existía o si llegan a reconocerse como obras de arte de especial relevancia, porque, tal situación no estaba prevista por el artista y pudiera interferir en su concepto y significado. En algunos casos su institucionalización tendrá que ser evaluada con respecto a otros valores contenidos en la propia obra. [figura 9]

Por otra parte, el mural realizado por ESCIF para el Institut Valencià d'Art Modern (IVAM) es una obra que surge de una residencia artística para la zona exterior del museo que se ha ofrecido públicamente al seguimiento de su proceso de degradación, puesto que es una obra efímera. Según menciona el museo, el artista se había basado en un trabajo de campo previo que duró seis meses, en los que se entrevistó con diferentes agentes de la zona para construir un archivo de símbolos y mensajes con los que estructurar el proyecto (IVAM, 2017).

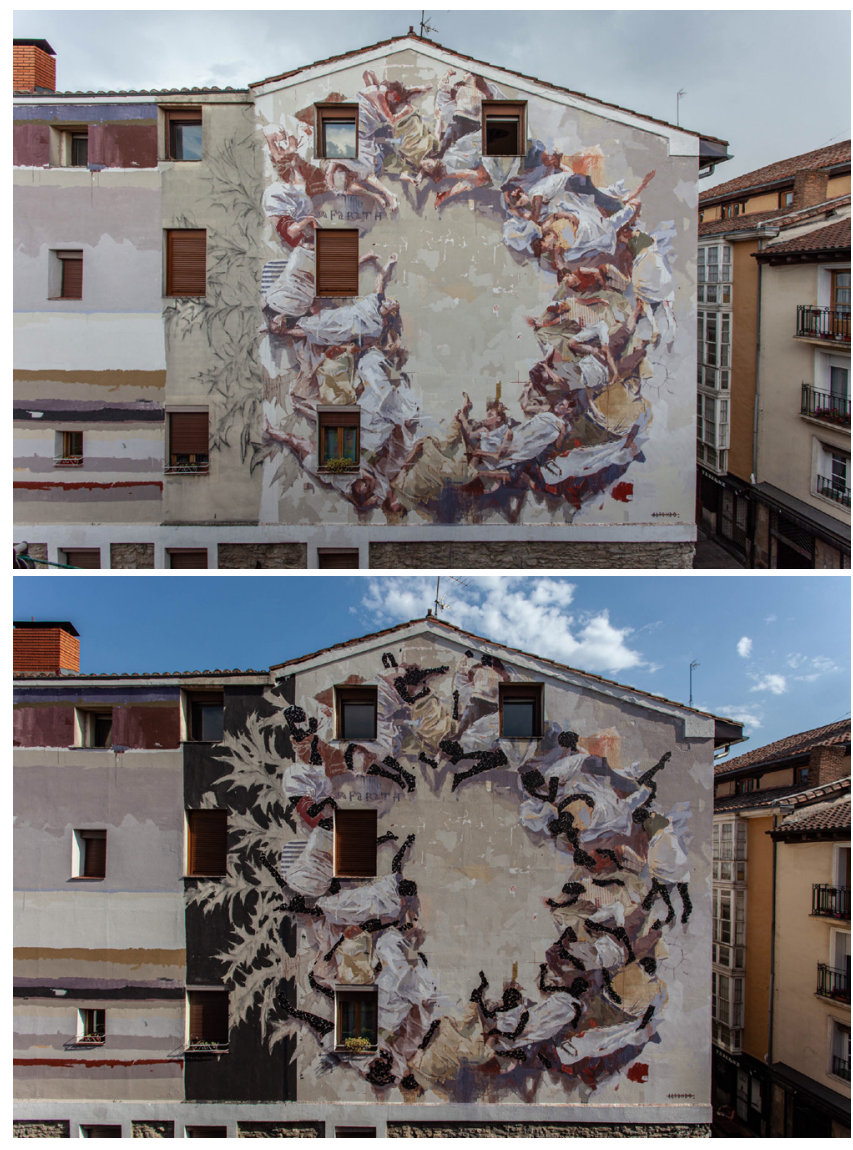

Figura 7 y 8.- "Lore Beltza". Obra de Gonzalo Borondo en Vitoria. Capa efímera experimental sobre silicatos. Fotos de Vincent Cornelli

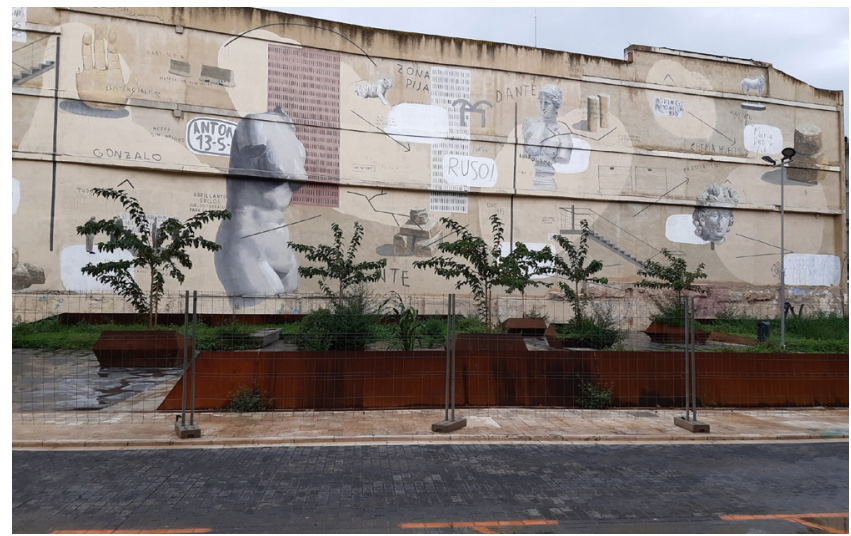

Figura 9.- IVAM produeix. Primera intervención exterior del IVAM (2017) en lo que hoy es el pati obert del museo. Fragmento del mural de ESCIF. Foto de Juan Antonio del Campo

Finalmente, la obra de SUSO33 en el exterior del Centro Atlántico de Arte Moderno (CAAM) que en 2009 formó parte de una exposición temporal de producción propia, con comisarios externos que han dejado muestra en su catálogo [7]. Esta obra que ha desaparecido recientemente por la esperada edificación en el solar en el que estaba, diez años después de su creación, fue objeto de un seguimiento fotográfico por parte del Centro Atlántico de Arte Moderno hasta cerrar su círculo vital (CAAM, 2009). [figura10] 


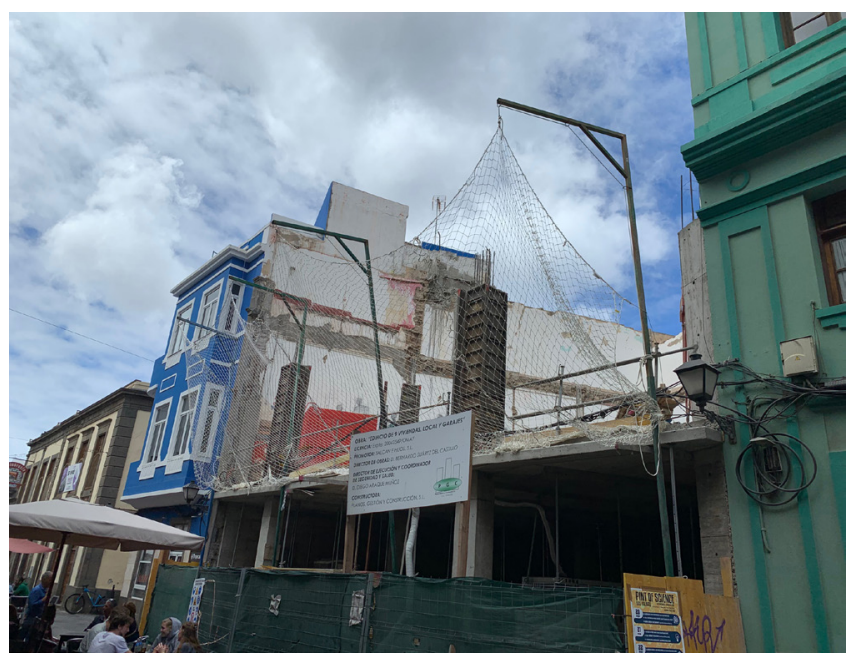

Figura 10.- Imagen izquierda la obra de Suso33 en las afueras del CAAM en 2009. Imagen derecha en 2019. Fotos de el CAAM

En estas tres obras se decidió que su faceta efímera fuera más o menos larga y también en los tres casos existe un seguimiento de su proceso de degradación.

El éxito de una obra de arte radica en su reconocimiento, sea de la naturaleza que sea y venga de donde venga. Cuando se solicita la conservación material de alguna de ellas, lo que se puede intentar es ralentizar su carácter efímero y las obras son mantenidas en su contexto con el consentimiento del artista. Esto es significativo cuando las obras encierran unas claves valiosas para la sociedad y por eso solo unas cuantas se asumen como patrimonio. En el tipo de obras artísticas por y para el espacio urbano, este proceso no debe alterar su titularidad y existirá un compromiso de servicio público para acceder a su contemplación.

\section{Conclusión}

El análisis de la relación entre museo y arte urbano suele provocar un error en el uso de la terminología y constituye una provocación intencionada por parte de las galerías, que usan ambos términos como nombres propios vacíos de contenido. La unión de estos conceptos tan diferentes constituye un contrasentido que no es posible justificar en un análisis en profundidad desde ninguno de los dos puntos de vista. A los museos se les supone un rigor científico, orden, sistema, pero sobre todo un reconocimiento y el catálogo de su colección. El muralismo contemporáneo se asocia a la idea de un pseudo arte urbano que es aceptado por las instituciones por su valor ornamental, que mantiene frescura en sus producciones y se asocia a futuro, novedad, intuición, pasión, rebeldía, espíritu crítico, independencia y sobre todo libertad, aunque sea el reflejo de una libertad perdida.

Para dar ese paso, las instituciones han trasladado el concepto musealizado de obras de la calle de los ochenta al siglo XXI, aprovechando la necesidad de profesionalización de los artistas y convirtiéndolos en muralistas para conseguir objetivos de promoción local y visibilidad. Por su parte, las galerías, situadas en el mercado del arte, aprovechan cualquier opción susceptible de ser mediática y útil desde el punto de vista comercial. El arte urbano aparece en estos museos y bajo esta terminología como un Disney World del arte, diseñado en el más puro estilo callejero. Todo esto, resulta ser lícito e incluso enriquecedor, aunque, necesitado de una estructura capaz de soportar la responsabilidad de contenidos. Por parte de la administración está pendiente la creación de una terminología propia y asumir un comisariado profesional que lleve a cabo el registro y acceso público digital de las obras, teniendo en cuenta que han sido subvencionadas con dinero público y el espacio para el que han sido encargadas.

Las diferencias de terminología no implican que los museos y centros de arte contemporáneo no puedan comunicar el resultado de todo este proceso performativo, sino que deben encontrar un procedimiento adecuado que no interfiera en las posibilidades de evolución del arte urbano, que seguirá persiguiendo, por su sendero particular, la utopía.

\section{Notas}

[1] Ulrich Blanché establece una diferencia entre arte urbano y street art, el primero se realiza con permiso y el segundo no. Elena G. Gayo en un "glosario básico" defiende una cuestión meramente idiomática e identifica un pequeño matiz de cercanía, en cuanto a actuar en la calle, street, o en la urbe, ciudad, es decir, que al analizar esta diferencia se subraya la relación de la obra y el artista con el entorno y el contexto, que será más o menos amplio, pero esto no afecta a la motivación.

[2] El artículo de Peio H. Riaño en el diario El País “Problemas para definir el museo del futuro" del 20 de agosto de 2019, menciona las palabras: inclusión, transparencia, dignidad, justicia, igualdad y bienestar para que se incluyan en la nueva definición de museo. Así como, el énfasis de la propuesta en el trabajo de los profesionales "de" museos y no de los profesionales "en" los museos. Términos, todos ellos, que no parece que puedan llegar a ser aceptados en la reunión de Kioto de 2019. https://elpais. com/cultura/2019/08/18/actualidad/1566148405 711078.html [última consulta 02-11-2019]

[3]. El enfoque de "lo rural" y "lo urbano" es una realidad cambiante que depende históricamente de la situación social en la que se quiera definir un entorno concreto y depende de muchos factores, tales como el grado de complejidad de la población o las diferencias de desarrollo y oportunidades económicas y sociales. Desde el punto de vista de la cultura, los medios de comunicación de masas contribuyen a impregnar todo el espacio homogeneizando el sentido de población y convirtiendo, según Lefebvre (1971:5), a toda la sociedad en urbana. 
[4] Además de las entrevistas publicadas en el anexo de este monográfico, se han tenido en cuenta las realizadas en vídeo a artistas internacionales y gestores como Jorge Rodríguez Gerada (gestor y artista de Avant Garde, Tudela) Jasper Wong y Jeff Gress de (Pow! Wow! Hawaii), Matthew Ortiz (Wooden Wave), Ron English, Set Globepainter, Inti, y un buen número de artistas cuya trayectoria se ha seguido desde 2010 y que no se publican en esta ocasión.

[5] El Muro por La Paz fue diseñado por el Servicio de Patrimonio del Ayuntamiento de Madrid y ejecutado por Ramón Polo. Plaza del Carmen. ABC Madrid 7-12-1982 pág. 38. Al ser una propuesta institucional nunca consiguió la acogida deseada.

[6] En 1898 se celebró en Bruselas el primer Congrès International de l'Art Public, al que siguieron otros cinco congresos internacionales con el mismo lema, que propiciaron la fundación en 1905 del Institut International de l'Art Public, cuyo órgano de expresión fue la revista editada desde 1907 a 1912.

[7] Exposición: Distorsiones, documentos, naderías y relatos. Las Palmas de Gran Canaria. Centro Atlántico de Arte Moderno (CAAM), 2009.

\section{Bibliografía}

ABREU, J.G. (2010) El concepto de arte público. Sus orígenes y significado actual. En Actas del Congreso internacional de críticos de arte 2009: Arte Público Hoy. Valladolid, ACYLCA, p. 17-29.

AZNAR Y. IÑIGO, M. (2007) Arte, política y activismo. Textos de la Universidad Complutense de Madrid.

http://webs.ucm.es/info/artepltk/textos/texto aznar inigo. html [02-11-2019]

BERNAL P. (1994) “Canteras viva, Atlántico sonoro”. Canarias7 Las Palmas de Gran Canaria. 8 de mayo de 1994

BLANCHÉ, U. (2015) Qu'est-ce que le Street art ? Essai et discussion des définitions. Cahiers de Narratologie [en linea] https://journals.openedition.org/narratologie/7397\#ftn15 [0211-2019]

CAAM (2009). Distorsiones, documentos, naderías y relatos. La Palmas de Gran Canaria: Centro Atlántico de Arte Moderno (CAAM)

CALVO SERRALLER, F.(1983) Fuengirola pone en su museo abierto de pintura al aire libre. La iniciativa forma parte de un plan municipal. El País 18-01-1983. https://elpais.com/ diario/1983/01/18/cultura/411692412 850215.html [02-112019]

CAPEL, H. (1975) La definición de lo urbano. Estudios Geográficos n¹38-139. Pág: 265-301
CASTLEMAN, C. (2012) Getting up. Hacerse ver. Capitán Swing

GARCÍA GAYO, E. (2011) ¿Se debe conservar el arte urbano basado en la premisa de: "piensa, crea, actúa y olvida"? en: Conservación de Arte Contemporáneo, 12 Jornada. MNCARS. GE-IIC. Madrid.

GARCÍA GAYO, E. (2018a:) Arte urbano. Herencia cultural. En VI Congreso del GEIIC. ¿Y después? Control y mantenimiento del Patrimonio Cultural, una opción sostenible / coord. por International Institute for Conservation of Historic and Artistic Works. págs. 306-313. Vitoria-Gasteiz.

GARCÍA GAYO, E. (2018b) Vermibus, de la calle al estudio y la galería. 19a Jornada de Conservación de Arte Contemporáneo. MNCARS, GEIIC. [Disponible en video] https://www.youtube. com/watch?v=wbTYuUIPBP0 (English subtitles) [02-11-2019]

GARCÍA GAYO, E. (2019). Murales urbanos. Una sucesión de capas de pintura perdurables y efímeras. 20a Jornada. MNCARS. GE-I/C. Madrid (pendiente de publicación)

GARSAN, C. (2017) En primera persona: así es el mural de Escif en el IVAM explicado por su autor. valenciaplaza.com (9-92017)

NATALIA MATEWECKI. (2014) Las figuras de espectador en el arte contemporáneo. Instituto de Historia del Arte Argentino y Americano. Facultad de BBAA. Universidad Nacional de La Plata. Boletín de Arte. Año 14, no 14.

LAZY, S (1995) Debate territory: toward a critical languaje for Public Art. Seatle. Washington. Buy Press.

LEFEBVRE, H: (1971:5) La ville et I'urbain. Espaces et sociétés. París

IVAM (2017) Inauguración de la intervención de Escif en el solar del IVAM. Actividades. https://www.ivam.es/es/actividades/ inauguracion-de-la-intervencion-de-escif-en-el-solar-delivam/ [02-11-2019]

PARRAMÓN, R. (2009). Arte y espacio público. ¿Campo de acción o campo de batalla? ¿Producto o servicio? Murría, Alicia (Dir.) Catálogo de la exposición: Distorsiones, documentos, naderías y relatos. La Palmas de Gran Canaria: Centro Atlántico de Arte Moderno (CAAM), 2009. http://ramonparramon.net/artey-espacio-publico-campo-de-accion-o-campo-de-batallaproducto-o-servicio/ [02-11-2019]

RAMÍREZ J.A. (1992: 197-207) Arte y arquitectura en la época del capitalismo triunfante. Visor

SÁNCHEZ.J.A. Coord. (2003). Nuevos espacios para el arte, en Práctica artística y políticas culturales: algunas propuestas desde la universidad. Universidad de Murcia. Campus digital: https://www.um.es/campusdigital/Libros/textoCompleto/ poliCultural/05asanchez.pdf [02-11-2019]

VAQUERO, J. M. (1980) Creado en Candás (Asturias) un 
museo al aire libre. El País. 7-nov-1980 https://elpais.com/ diario/1980/11/07/cultura/342399611_850215.html [02-112019]

YVARS. J.F. (2005) El espacio intermedio. Apreciaciones sobre el arte moderno. Debolsillo

\section{Autor/es}

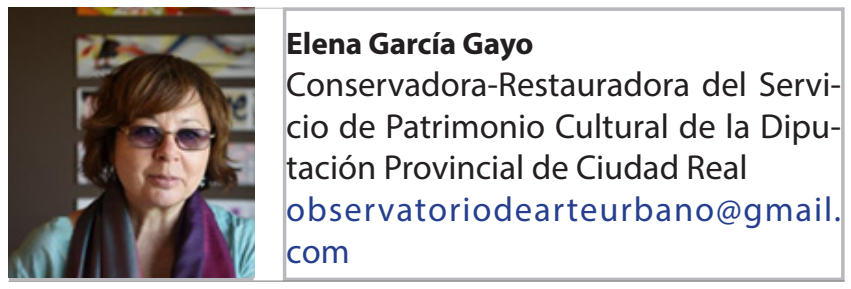

Elena García Gayo es titulada en Conservación Restauración de Bienes Culturales por la ESCRBC de Madrid. ConservadoraRestauradora del Servicio de Patrimonio Cultural de la Diputación Provincial de Ciudad Real. Paralelamente, es coordinadora de los grupos de trabajo, y del de Arte Urbano, del grupo español del International Institute for Conservation, GEIIC, desde 2015. Colabora con la Comisión de Seguimiento del Plan Nacional de Conservación del Patrimonio Cultural del siglo XX en representación del GEIIC. Crea y administra el Observatorio de Arte Urbano. Dirige y edita la revista digital especializada Mural Street Art Conservation. Coordinó el primer monográfico anexo al n¹0, Arte Urbano: Conservación y Restauración de intervenciones contemporáneas, publicado en la revista digital ge-conservación, en 2016.

http://observatoriodearteurbano.org

https://independent.academia.edu/EGayo 